\title{
ANÁlise do uso de SIG NO ROTEAMENTO dos Veículos de COLETA DE RESÍDUOS SÓLIDOS DOMICILIARES
}

\section{ANALYSIS OF THE USE OF GIS IN THE COLLECTING VEHICLE ROUTING OF DOMESTIC SOLID WASTE}

\begin{abstract}
LUZENIRA ALVES BRASILEIRO
Doutora em Transportes pela Escola de Engenharia de São Carlos - EESC/USP. Professora do Departamento de Engenharia Civil da Faculdade de Engenharia de Ilha Solteira - FEIS/UNESP

\section{MÁRCIO GONÇALVES LACERDA}

Engenheiro Civil pela Faculdade de Engenharia de Ilha Solteira - FEIS/UNESP. Mestre em Engenharia Civil, na área de Recursos Hídricos e Tecnologias Ambientais pela Faculdade de Engenharia de Ilha Solteira - FEIS/UNESP
\end{abstract}

Recebido: 29/06/07 Aceito: 07/10/08

\section{RESUMO}

Relata-se neste trabalho, a análise do uso de um Sistema de Informação Geográfica - SIG como ferramenta para roteirização de veículos de coleta de resíduos sólidos domiciliares. O software utilizado foi o TransCAD, versão 3.2, que permite desenvolver rotas utilizando algoritmos que incluem o procedimento de roteirização em arco. O objetivo é minimizar a extensão total a ser percorrida pelos veículos coletores. $\mathrm{O}$ estudo de caso foi realizado na cidade de Ilha Solteira - SP. Os dados coletados e os resultados obtidos pelo TransCAD foram processados no software Microsoft Excel. Os resultados obtidos demonstraram reduções percentuais de até $41 \%$ na distância total percorrida e de $68 \%$ no tempo total de percurso em relação ao serviço atual.

PALAVRAS-CHAVE: SIG, roteirização de veículos de coleta, resíduos sólidos domiciliares.

\begin{abstract}
The use of Geographical Information System - GIS as a tool for the routing of the collecting vehicles of domestic solid waste was analyzed. The software TransCAD, version 3.2, was used. This GIS is used to develop routes by algorithm that includes a procedure of arc routing (Routine Arc Routing). The objective is to minimize the total distance travelled by the collecting vehicles. The case study was carried out in Ilha Solteira city. The collected data and the results obtained by TransCAD had been processed using the software Microsoft Excel. The results obtained showed that there was a decrease of $41 \%$ in the total distance and $68 \%$ in the total time compared to the current service.
\end{abstract}

KEYWORDS: GIS, collecting vehicle routing, domestic solid waste.

\section{INTRODUÇÃO}

Independente do tamanho do município, o poder público municipal incentiva o desenvolvimento econômico local, aumentando a produção agrícola, atraindo indústrias e expandindo as atividades voltadas ao comércio e à prestação de serviços, sem levar em conta uma contrapartida do crescimento econômico, que é o aumento da produção de lixo.

Os problemas ligados aos recursos básicos para manter uma cidade em funcionamento têm aumentado devido ao rápido crescimento populacional e ao processo de urbanização (forma de ocupação do solo) que ocorreu nas últimas décadas. Enquanto a forma de ocupação do solo dificulta o acesso da população aos serviços de coleta de lixo e, também, aumenta o custo de transporte dos resíduos coletados, o crescimento populacional aumenta a quantidade de lixo produzida, significando maior custo para a manutenção dos serviços. Somando-se a isto, existe a forma desorganizada de como as prefeituras têm conduzido estes serviços. Segundo Leite (apud Roviriego, 2005), no Brasil, a responsabilidade pela gestão dos resíduos sólidos domiciliares compete aos municípios, que enfrentam dificuldades no setor, tal como o despreparo técnico e gerencial do pessoal designado para acompanhar todas as etapas que a questão dos resíduos sólidos exige.

Esse problema é, ainda, mais acentuado em cidades de pequeno porte; onde, na grande maioria, os sistemas de limpeza pública são operados com soluções locais. No entanto, estas soluçôes acabam sendo dificultadas por condições existentes, tal como limitação financeira, devido à orçamentos inadequados e arrecadação insuficiente. Em muitas situaçōes, isto faz com que haja uma redução da cobertura do serviço de coleta de lixo.

Para Deluqui (1998), a otimização do processo de coleta deve buscar a máxima satisfação da população com a prestação de serviços através da adequada consideração dos aspectos de qualidade, custos, atendimento e proteção à saúde pública. Sendo assim, é fundamental que se estabeleça um controle operacional dos serviços prestados que permita a avaliação dos mesmos.

A operação de coleta, especificamente, absorve uma considerável fatia dos recursos municipais destinados à limpeza urbana. Desta forma, torna-se importante um serviço bem planejado. $\mathrm{O}$ presente trabalho visa analisar o uso de SIG (Sistema de Informação Geo- 
gráfica) na coleta de resíduos sólidos domiciliares em cidade de pequeno porte. A existência de uma representação da rede de uma cidade através de um SIG pode conferir representatividade e fidelidade às condiçỗes reais em que os deslocamentos do veículo coletor ocorrem.

\section{ROTEIRIZAÇÃO DE VEÍCULOS DE COLETA DE RESÍDUOS SOLIDOS DOMICILIARES}

A roteirização de veículos é a definição de uma ou mais rotas a serem percorridas por veículos de uma frota, passando por locais que devem ser visitados (Brasileiro, 2004). Estes locais podem ser pontos específicos, caracterizados como nós de uma rede ou segmentos de vias. Os segmentos de vias são denominados arcos ou ligaçôes.

A roteirização de veículos pode ser classificada em três tipos de problema: problema de cobertura de nós (quando a coleta é realizada em pontos específicos), problema de cobertura de arcos (quando a coleta é realizada em segmentos de vias) e problema geral de roteirização (quando a coleta é realizada em nós e arcos). O roteamento dos veículos de coleta de lixo domiciliar é um Problema de Roteirização em Arcos (Arc Routing Problem - ARP) (Eiselt et al, 1995).

A operação de coleta dos resíduos sólidos domiciliares caracteriza-se pelo envolvimento dos cidadãos, que devem acondicioná-los adequadamente e apresentá-los em dias, locais e horários pré-estabelecidos. Este serviço consiste em transportar os resíduos dos locais de onde foram acondicionados até o destino final. Para que o serviço de coleta de lixo ocorra de forma satisfatória, é necessário a implantação de um sistema eficiente, que opere em toda a área urbana e; também, que seja regular, ou seja, os veículos coletores devem passar regularmente nos mesmos locais, dias e horários.

De acordo com IPT e CEMPRE (2000), os serviços de limpeza absorvem entre 7 e $15 \%$ dos recursos de um orçamento municipal, dos quais cerca de $50 \%$ são destinados à coleta e ao transporte dos resíduos. Por esta razão, as operaçóes de coleta e transporte são serviços importantes para a administração da cidade.

O objetivo do roteamento na coleta de lixo é definir um conjunto de rotas que atendam a um conjunto de determinadas áreas. A meta é realizar o percurso com o menor custo em termos de quilometragem e tempo total, atendendo às restriçôes de movimentação dos veículos nas ruas da cidade, capacidade dos caminhôes e tempo de serviço máximo da frota.

As rotas dos veículos podem ser definidas utilizando técnicas não matemáticas ou matemáticas (Brasileiro, 2004). As técnicas não matemáticas são denominadas de método empírico. As técnicas matemáticas utilizam algoritmos e a roteirização pode ser realizada por método manual ou computacional. No método computacional, o algoritmo é integrado a um software denominado de roteirizador. Um software do tipo roteirizador define a melhor rota, segundo a variável que se quer otimizar - distância ou tempo de viagem. Outros softwares, além de definir a rota, produzem um mapeamento computadorizado e permitem modificar o banco de dados, gerando diferentes rotas e proporcionando a escolha da melhor rota, segundo uma análise dos diversos cenários. Estes softwares são denominados de SIG. O SIG utilizado em problemas de transporte é chamado de SIG-T.

\section{ESTUDO DE CASO}

O estudo de caso foi realizado para a cidade de Ilha Solteira, localizada na região noroeste do Estado de São Paulo a, aproximadamente, $670 \mathrm{~km}$ de distância da capital. A cidade possui uma população de aproximadamente 24.000 habitantes.

O responsável pela execução dos serviços de coleta de resíduos sólidos domiciliares é a própria Prefeitura Municipal. Na Tabela 1 são ilustrados os dados representativos do serviço, durante uma semana de operação.

Os resíduos sólidos domiciliares são coletados diretamente nas residên- cias e acondicionados em sacos plásticos ou caixas de papelão. A operação de coleta ocorre no período da manhã. Nas segundas-feiras e nos dias após os feriados, quando a quantidade de resíduo gerado está acumulada, há a necessidade da realização de uma coleta adicional no período da tarde. No período da manhã, a coleta ocorre das 7:00 h às 12:00 h e, quando necessário no período da tarde, o serviço é realizado das 14:00 h até por volta das 16:00 h.

Atualmente, a frota é composta por três veículos. Os veículos dispóem de caçamba metálica fechada, com dispositivo hidráulico de prensagem ou compactação, que permite a redução de volume aparente do lixo. Dois veículos têm capacidade para 8 t e um veículo tem capacidade para $5 \mathrm{t}$. Todos os veículos se encontram em bom estado de conservação, não apresentando problemas operacionais que prejudiquem a execução do serviço.

O plano de operação divide a cidade em três setores de coleta, sendo que cada um é coberto por um único veículo. Cada veículo possui uma equipe de três garis e um motorista. Para cada setor de coleta, é proposto um itinerário a ser cumprido pelo veículo coletor. O roteiro de coleta é definido pelo próprio motorista, baseado na sua experiência.

Quando o veículo atinge aproximadamente a carga máxima, o motorista o conduz para o local de destinação final. Depois de descarregado, se o veículo já tiver cumprido seu serviço, ele deverá retornar à garagem. Caso contrário, deverá reiniciar a operação de coleta, a partir do ponto de onde parou.

\section{MATERIAIS E MÉTODO}

O método de roteirização utilizado atualmente no caso em estudo é o empírico. $\mathrm{O}$ método de roteirização utilizado neste trabalho é o computacional. $\mathrm{O}$

Tabela I - Produção de resíduo domiciliar em Ilha Solteira - SP

\begin{tabular}{cc}
\hline Dia & Produção $(\mathrm{kg})$ \\
\hline Segunda-feira & 21.670 \\
Terça-feira & 11.019 \\
Quarta-feira & 10.989 \\
Quinta-feira & 11.055 \\
Sexta-feira & 9.803 \\
Sábado & 9.223 \\
\hline
\end{tabular}


software utilizado é o TransCAD, que é considerado um Sistema de Informação Geográfica para Transportes (SIG-T). Este software permite desenvolver rotas, utilizando o algoritmo denominado $A r c$ Routing, que realiza o procedimento de roteirização em arco.

A análise de uso de um Sistema de Informação Geográfica na roteirização de veículos de coleta de resíduos sólidos domiciliares, a fim de minimizar a distância total de viagem, é realizada através da comparação dos roteamentos definidos por método empírico e por método computacional. Neste caso, o método computacional simula rotas para o serviço estudado, em todo seu universo. A simulação da roteirização dos veículos é realizada com base nos dados coletados no sistema real.

Os dados foram tabulados de forma a serem inseridos nos arquivos de entrada do software TransCAD. Há quatro passos principais para solucionar o problema de roteamento de veículos usando o TransCAD.

(1) Preparar os dados de entrada

Deve-se preparar arquivos geográficos que contêm a localização dos depósitos e das paradas, juntamente com informaçôes sobre a demanda. Basicamente, é necessário dois arquivos de entrada: o arquivo de paradas (stop layer) e o arquivo de veículos (vehicle table). Os depósitos e as paradas devem estar no mesmo arquivo geográfico, que é referido como o arquivo de paradas (stop layer). $\mathrm{O}$ arquivo de paradas deve ter os seguintes campos: ID (um número que identifica especificamente a parada); Name (um nome ou número que é usado para identificar a parada nos relatórios de rota); Demand (a demanda na parada); Open Time (o tempo inicial que a parada pode ser servida); e Close Time (o tempo final que a parada pode ser servida). Para solucionar o problema de roteamento de veículos com janelas de tempo, deve-se também preparar um arquivo de veículos (vehicle table). Este arquivo contém informaçōes específicas para cada tipo de veículo. $\mathrm{O}$ arquivo de veículos deve ter os seguintes campos: Depot ID (a identificação do nó do depósito para cada tipo de veículo); Type (código do tipo de veículo); Capacity (a capacidade de cada tipo de veículo); Num_vehs (o número de veículos de cada tipo); e Cost (o custo de aquisição/operação/aluguel de cada tipo de veículo).
(2) Criar a matriz de roteamento (matriz origem/destino)

A rotina Routing Matrix cria o arquivo da matriz que contém a distância e o tempo de viagem entre cada depósito e parada e, entre cada par de paradas. Para criar uma matriz de roteamento, deve-se escolher o seguinte: quais paradas incluir, quais depósitos incluir e qual método usar para medir a distância e o tempo. Pode-se escolher como calcular distâncias e tempos de viagem entre duas formas diferentes: usando uma rede ou usando conexôes em linha reta entre pontos. O método de rede é mais preciso e permite criar um sistema de rotas com o roteamento resultante, mas requer maior preparação de dados. As rotas criadas pela matriz de roteamento, usando o método de conexões em linha reta entre pontos, não podem ser exibidas como um sistema de rotas sobre um mapa.

(3) Solucionar o problema de roteamento de veículos

A rotina Vehicle Routing desenvolve rotas de veículos e produz relatórios e itinerários. Esta rotina identifica rotas que servem um conjunto de paradas, a partir de um conjunto de depósitos. Para usar a rotina Vehicle Routing, devese: escolher o conjunto de depósitos onde os veículos iniciam e terminam suas viagens, escolher o conjunto de paradas a serem servidas, identificar a capacidade dos veículos no arquivo de veículos (vehicle table) e identificar a demanda de cada parada no arquivo de paradas (stop layer). A rotina Vehicle Routing produz dois ou três arquivos de saída: (1) Um arquivo de texto contendo o itinerário de cada veículo; (2) Uma tabela contendo a listagem das paradas em cada rota (este relatório é produzido somente se a matriz de roteamento for definida pelo método de rede); e (3) Um arquivo de relatório resumido (este arquivo é produzido se a opção Procedure Report File é ativada na caixa de diálogo Procedure Settings.

\section{(4) Apresentar os resultados}

Se a matriz de roteamento for criada pelo método de rede, as rotas produzidas pela rotina Vehicle Routing podem ser convertidas em um arquivo de sistema de rotas, através da rotina Display Vehicle Routes. Esta rotina exibe as rotas sobre um mapa e edita as mesmas, permitindo analisar filas ou fazer análises espaciais de qualquer rota ou combinaçãa de rotas. Para criar um sistema de rotas, mostrando o rote- amento dos veículos, deve-se fornecer as seguintes informaçóes: o nome da tabela de viagens que foi produzida pela rotina Vehicle Routing e a rede que foi usada para criar a matriz de roteamento (matriz origem/destino).

\section{RESULTADOS E DISCUSSÕES}

Os resultados do estudo foram analisados através dos arquivos de saída de dados produzidos pelo software. As simulaçôes, utilizando a rotina $A r c$ Routing, foram realizadas considerando a divisão dos setores determinados pelo serviço de coleta atual. A cidade de Ilha Solteira apresenta três setores de coleta, sendo denominados de Setor 1, Setor 2 e Setor 3. Na Figura 1 é apresentada a localização geográfica destes setores.

Com a base de dados concluída, criou-se a rede de transportes considerando, o sentido de ruas e as restriçóes de movimento, particularmente para retornos em $\mathrm{U}$, que são movimentos difíceis e perigosos de serem executados. As vias preferenciais são determinadas pelo próprio software TransCAD, utilizando-se das variáveis tempo e distância em cada segmento de via. A representação gráfica do roteamento está apresentada na Figura 2.

As Figuras 3 e 4 apresentam graficamente os valores de distância e tempo total de viagem, para cada dia de coleta, encontrados através da roteirização feita pelo motorista do veículo (método empírico) e da roteirização feita através da rotina Arc Routing (método computacional). A redução significa a diferença entre o valor obtido pelo método empírico e pelo método computacional, ou seja, a economia total em cada dia.

As informaçôes constantes nas Figuras 3 e 4 permitiram uma avaliação quantitativa dos parâmetros operacionais do serviço de coleta domiciliar. Esta avaliação tornou-se importante pelo fato de se considerar os dados de uma semana de operação do serviço, pois representa o ciclo em que o processo de coleta se repete, levando-se em consideração as oscilaçōes naturais entre os parâmetros durante esse período de tempo.

Em termos gerais, os valores das variáveis que representam os percursos totais coletados foram superiores aos valores simulados nos três setores de coleta estudados. Algumas vezes, os 


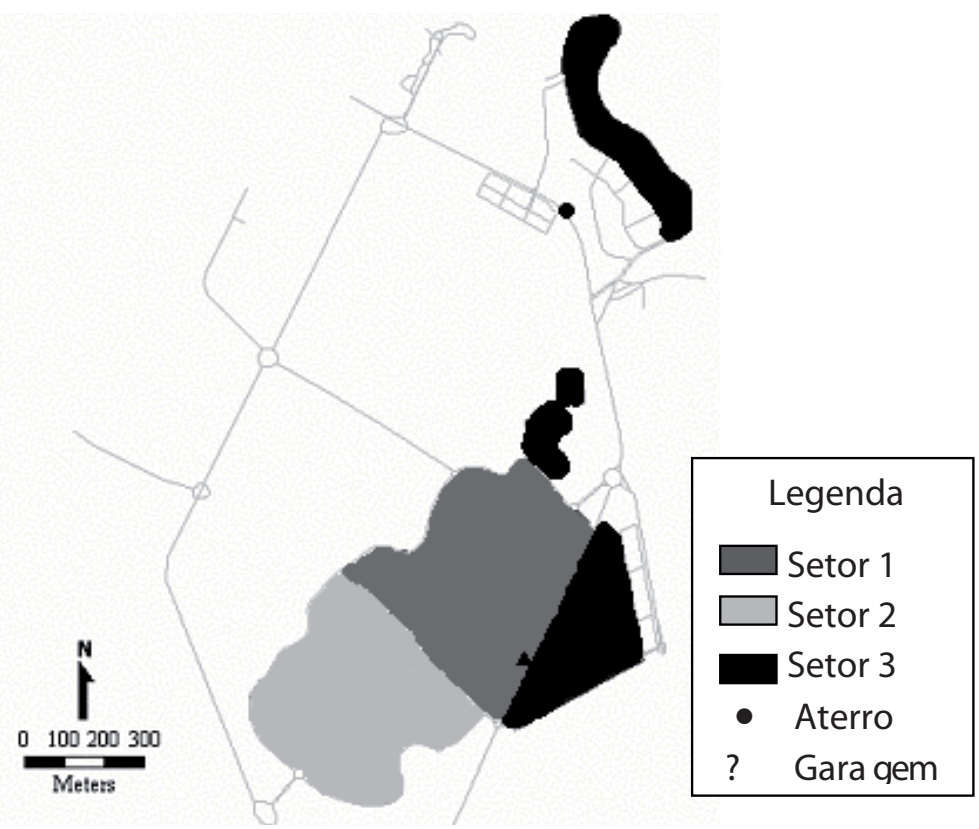

Figura I - Setores de coleta de resíduos sólidos domiciliares em Ilha Solteira - SP

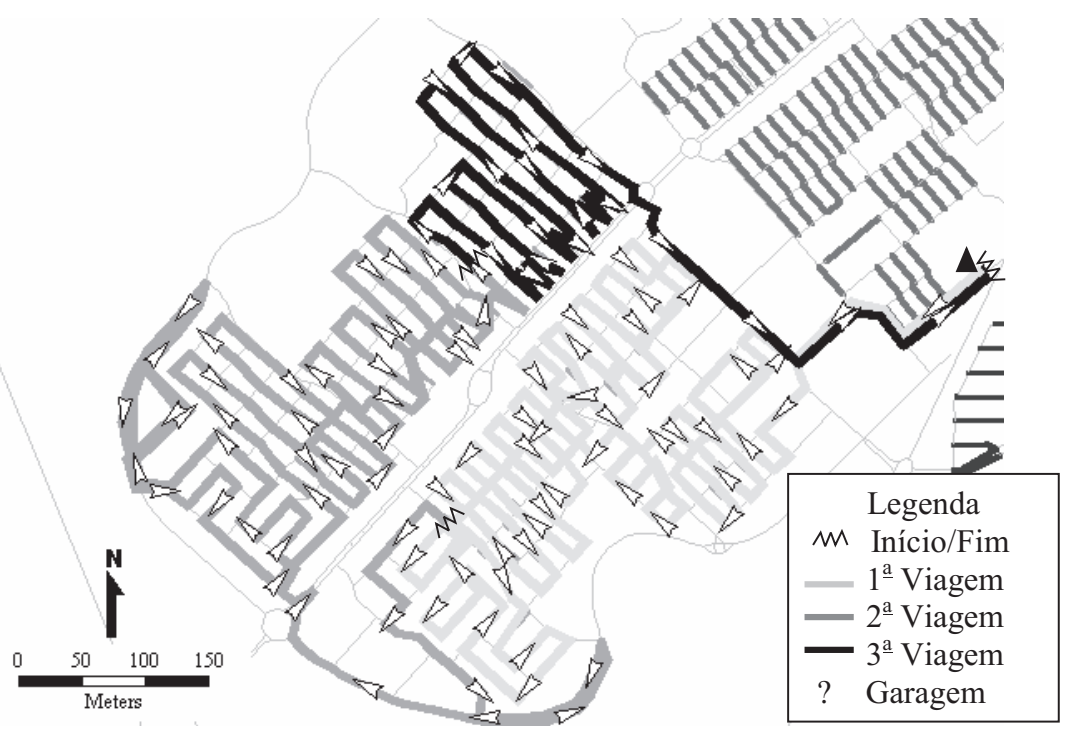

Figura 2 - Roteamento do veículo coletor na segunda-feira para o Setor 2

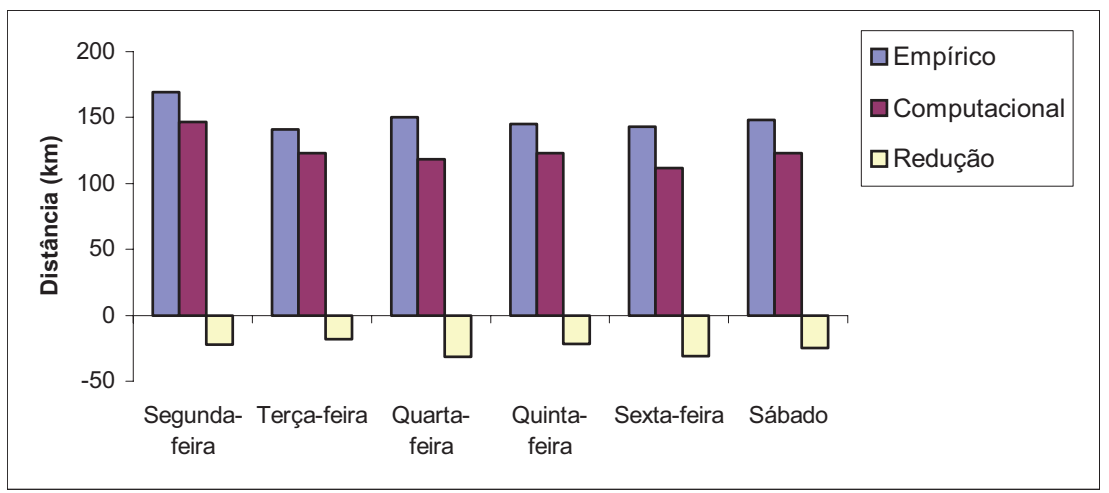

Figura 3 - Distância total de viagem para cada dia de coleta 


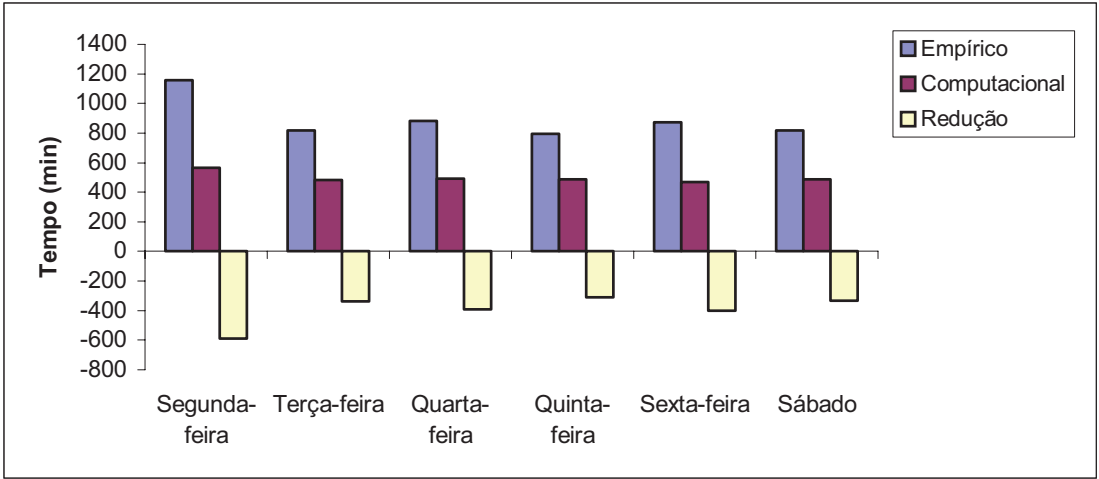

Figura 4 - Tempo total de viagem para cada dia de coleta

resultados demonstraram reduções bastante significativas, tanto de distância quanto de tempo de serviço. Isto é devido ao fato de que o roteamento simulado resultou em um número menor de viagens do que na situação real. Então, houve uma diminuição do percurso vazio, consequentemente, diminuiu os percursos totais.

A rota de coleta em cada setor, em algumas situaçóes, apresentou valores percentuais positivos em relação ao serviço atual. Isto demonstra que o sistema atual não percorre todas as ruas que necessitam ser atendidas. Ao contrário do que ocorre com o roteamento determinado pela simulação, onde todas as ruas são atendidas pelo serviço em todos os dias da semana.

$\mathrm{O}$ percurso sem coleta apresentou redução em todos os dias e em todos os setores. A análise deste parâmetro mostra que atualmente o veículo não se movimenta de uma forma eficiente quando está fora da rota de coleta. $\mathrm{O}$ veículo tem percorrido grandes distâncias e, em conseqüência, resulta em um grande tempo de execução do serviço.

Todas as simulações foram realizadas com o intuito de verificar a eficiência da utilização de SIG no roteamento de veículos de coleta de resíduos sólidos domiciliares. Através dos resultados, pôde-se obsevar que o SIG é aplicável para este tipo de estudo, pois apresentou reduções significativas em termos de distância e tempo total de percurso.

\section{CONCLUSÕES}

A aplicação do SIG TransCAD apresentou, através dos resultados obtidos, reduções percentuais de até $41 \%$ na distância total percorrida e, de $68 \%$ no tempo total de percurso, em relação ao serviço atual. A determinação dos parâmetros operacionais de coleta foi importante para este estudo, pois tornou possível a comparação entre a situação real e a situação simulada pelo software.

Dentre as vantagens da utilização do TransCAD para roteirização de veículos de coleta de resíduos sólidos domiciliares, pode-se citar: a produção de uma solução de roteirização em menor tempo; a utilização de valores reais de distância e tempo de percurso em toda a rede viária; a possibilidade de análise de mudança dos valores das variáveis, tais como frota e período de operação e; também, a possibilidade de análise de mudança de restriçōes, tais como capacidade dos veículos e regras de tráfego.

Por outro lado, a utilização do TransCAD pode apresentar uma desvantagem, como por exemplo, a rotina Arc Routing não considera o local de descarga no roteamento do veículo coletor. O veículo parte da garagem, realiza todo o percurso de coleta e em seguida retorna à garagem. Assim, para o cálculo das distâncias adicionais não consideradas na aplicação da rotina, foi necessário utilizar os procedimentos de caminho mínimo (shortest path).

A aplicabilidade de um SIG deve ser analisada não somente pelo aspecto econômico, mas também pelo aspecto ambiental a que estão relacionados os resíduos sólidos domiciliares, já que um eficiente sistema de coleta e transporte de resíduo sólido deve minimizar todo tipo de poluição, seja do solo, ar ou água. Além disto, um sistema eficiente de coleta e transporte de resíduos sólidos urbanos deve ajudar a melhorar o aspecto estético da cidade, a fim de tornar mais agradável a vida de seus moradores, evitando a poluição visual. Um sistema que permita alcançar estas metas com menor custo possível é de- sejável; mas, muitas vezes, os recursos técnicos e financeiros das entidades responsáveis pela limpeza urbana são limitados.

\section{REFERÊNCIAS}

BRASILEIRO, L.A. Análise do Roteamento de Veículos na Coleta de Resíduos Domésticos, Comerciais e de Serviços de Saúde. Tese de LivreDocência, Universidade Estadual Paulista, 94 p. Ilha Solteira. 2004.

DELUQUI, K.K. Roteirização para veículos de coleta de residuos sólidos domiciliares utilizando um sistema de informação geográfica - SIG. Dissertação de Mestrado - Universidade de São Paulo, Escola de Engenharia de São Carlos. 218 p. São Carlos. 1998.

EISELT, H.A.; GENDREAU, M.; LAPORTE, G. Arc routing problems, part I: the chinese postman problem. Operation Research, v. 43, n. 2, p. 231-242. 1995.

IPT e CEMPRE. Lixo Municipal: Manual de Gerenciamento Integrado. 2. ed. São Paulo. Ed. IPT, 370 p. 2000.

ROVIRIEGO, L.F.V. Proposta de uma metodologia para a avaliação de sistemas de coleta seletiva de resíduos sólidos domiciliares. Dissertação de Mestrado - Universidade de São Paulo, Escola de Engenharia de São Carlos.191 p. São Carlos. 2005.

Endereço para correspondência:

\section{Luzenira Alves Brasileiro}

Alameda Bahia, $\mathbf{5 5 0}$

Centro - Ilha Solteira - SP - Brasil I5385-000 Ilha Solteira - SP -

Brasil

Tel: (I 8) 3743- I 2 I6

Fax: (I 8) 3743-I I 60

E-mail: luzenira@dec.feis.unesp.br 